\title{
Lixiviação de imidazolinonas em resposta a diferentes manejos de irrigação em solo de cultivo de arroz irrigado
}

\author{
Imidazolinone leaching in response to different irrigation management on rice cultivated soil
}

\author{
Angela Da Cas Bundt ${ }^{\mathrm{I}}$ Luis Antonio de Avila ${ }^{\mathrm{I}}{ }^{*}$ Dirceu Agostinetto ${ }^{\mathrm{II}}$ \\ João Paulo Refatti ${ }^{\mathrm{I}}$ Luciano Cassol $^{\mathrm{III}}$ Fernanda Costa Rockemback ${ }^{\mathrm{III}}$
}

RESUMO

\begin{abstract}
Os herbicidas utilizados no Sistema Clearfield ${ }^{\circledast}$ de produção de arroz irrigado caracterizam-se por serem móveis no solo. Tal mobilidade contribui para a contaminação ambiental e intensificação do residual no solo. A irrigação por inundação utilizada na lavoura arrozeira é uma das principais causas de livixiação de imidazolinonas, contudo, manejos alternativos de irrigação podem contribuir para sua diminuição. Assim, o objetivo do trabalho foi estimar, através de bioensaio, a lixiviação de imidazolinonas frente a diferentes manejos de irrigação. Para isso, foram conduzidos dois experimentos em casa de vegetação e em colunas de solo. Em ambos, foram testados três manejos de irrigação, sendo eles: contínuo, intermitente e capacidade de campo. Os herbicidas foram aplicados na superfície do solo e, após 48 horas, iniciou-se a irrigação. Aos 45 e 90 dias de irrigação, para o primeiro e segundo experimentos, respectivamente, as colunas de solo foram cortadas longitudinalmente e realizouse bioensaio utilizando solo das diferentes profundidades. Os resultados permitem concluir que a mistura formulada imazapic + imazapyr apresenta maior lixiviação. Para os herbicidas testados isoladamente, o imazapic lixivia mais, seguido do imazethapyr e imazapyr. Os manejos de irrigação contínuo e intermitente não diferem entre si e promovem maior lixiviação dos herbicidas, quando comparado ao solo na capacidade de campo.
\end{abstract}

Palavras-chave: contaminação do solo, herbicida, Oryza sativa, transporte.

\section{ABSTRACT}

Herbicides used in Clearfield ${ }^{\varpi}$ rice system are characterized to be mobile in soil. This mobility contributes to environmental contamination and intensifies the residual in the soil, due to the upward movement during the off-season. The flooded irrigation used on rice crops is the main cause of imidazolinones leaching. However, alternative practices can be used to minimize leaching of herbicides. This research aimed to evaluate the effects of different irrigation management on leaching of imidazolinone herbicides. For this, two experiments were conducted using soil columns in a greenhouse and testing three irrigation managements: continuous, intermittent and field capacity. The herbicides were applied to soil surface and after 48 hours irrigation started. At 45 and 90 days of irrigation for the first and second trials, respectively, bioassay was carried out using different soil layers. Results showed that the formulated mixture of imazapyr + imazapic showed the greatest leaching potential. For individually herbicides tested, imazapic was the most leached one, followed by imazethapyr and imazapyr. Continuous and intermittent irrigation managements did not differ and promoted greater leaching potential of herbicides compared to soil at field capacity.

Key words: soil contamination, herbicide, Oryza sativa, transport.

\section{INTRODUÇÃO}

O Sistema Clearfield ${ }^{\circledast}$ de produção de arroz irrigado caracteriza-se pela utilização de cultivares resistentes a herbicidas pertencentes ao grupo químico das imidazolinonas. Ambos os herbicidas utilizados nessa tecnologia são compostos por misturas formuladas, sendo $\mathrm{o}$ Only ${ }^{\circledast}$ (imazethapyr+imazapic, $75+25$ g i.a. $\mathrm{L}^{-1}$, respectivamente) e o Kifix ${ }^{\circledast}$ (imazapyr+imazapic, $525+175 \mathrm{~g}$ i.a. $\mathrm{kg}^{-1}$, respectivamente) os que possuem registro pelo Ministério da Agricultura, Pecuária e Abastecimento (AGROFIT, 2013).

\footnotetext{
'Programa de Pós-graduação em Fitossanidade, Departamento de Fitossanidade, Universidade Federal de Pelotas (UFPEL), Pelotas, RS, Brasil.

"Departamento de Fitossanidade, Faculdade de Agronomia Eliseu Maciel (FAEM), UFPEL, CP 354, 96010-900, Pelotas, RS, Brasil. E-mail:laavilabr@gmail.com. *Autor para correspondência.

${ }^{\text {IIIC } C u r s o ~ d e ~ A g r o n o m i a, ~ F A E M, ~ U F P E L, ~ P e l o t a s, ~ R S, ~ B r a s i l . ~}$
} 
Um aspecto importante na dinâmica das imidazolinonas no solo é a mobilidade através do perfil. O baixo coeficiente de adsorção e a elevada solubilidade em água fazem com que sejam relativamente móveis no solo (LOUX \& REESE, 1993). A mobilidade vertical desses herbicidas é bastante pronunciada, em relação ao horizontal (TU et al., 2004). Estudos mostram que 80 a $90 \%$ do herbicida aplicado pode se concentrar na camada de 10 a $20 \mathrm{~cm}$ de profundidade no perfil do solo, podendo permanecer neste local por longos períodos (LOUX \& REESE, 1993).

A associação dessa mobilidade juntamente com a limitada degradação desses herbicidas no solo é o principal fator responsável pelos problemas relacionados, tanto com a persistência no solo como a própria contaminação ambiental. Isso ocorre porque a principal forma de degradação de imidazolinonas no solo é através da atividade microbiana (LOUX et al., 1989; FLINT \& WITT, 1997). Ao movimentarse para maiores profundidades, tal degradação torna-se limitada, devido à baixa atividade de microrganismos degradadores e baixos níveis de oxigênio, principalmente em condições de cultivo de arroz irrigado, que permanecem com lâmina de irrigação durante quase todo ciclo da cultura.

Outro fator importante é que a mobilidade das imidazolinonas no solo não se limita apenas ao movimento vertical descendente. Tais herbicidas podem movimentar-se ascendentemente ao longo do perfil, de acordo com as oscilações do lençol freático (FIRMINO et al., 2008; BUNDT, 2013), sendo essa uma das possíveis explicações para os problemas de efeito residual do herbicida em condições de solo de cultivo de arroz, ou seja, o retorno para a superfície do solo durante a entressafra, após o mesmo ter lixiviado no período de cultivo do arroz.

Convém ressaltar também que a lixiviação de imidazolinonas é diretamente influenciada pelo volume de água percolado ao longo do perfil do solo. Essa afirmação é embasada em estudos realizados por MONQUERO et al. (2008), que observaram maior lixiviação dos herbicidas imazapic e imazapyr por influência de maiores volumes de precipitações pluviais ou de irrigações artificiais.

O cultivo de arroz irrigado no Estado do Rio Grande do Sul é fundamentalmente conduzido sob irrigação por inundação, caracterizada pela permanência de uma lâmina de água sobre a superfície do solo durante praticamente todo o ciclo da cultura. Esse tipo de irrigação, além de utilizar grandes volumes de água, pode influenciar o movimento de alguns herbicidas aplicados na cultura. Nesse caso, a irrigação contribuiria para a maior lixiviação desses herbicidas, devido à pressão hidráulica exercida pela lâmina de água durante o cultivo do arroz. Nesse contexto, a irrigação intermitente surge como alternativa, devido à utilização de lâmina de água mais baixa, propiciando maior armazenamento de água da chuva e menor lixiviação de herbicidas, devido à forma como é conduzida, ou seja, pela evaporação da lâmina de água para a sua posterior reposição. Tal manejo de irrigação mantém índices de produtividade semelhantes à irrigação por inundação contínua (BELDER et al., 2004; MARTINI et al., 2011), porém com menor consumo de água.

A hipótese do presente estudo é de que manejos de irrigação que promovam menor utilização de água diminuem a lixiviação de herbicidas por proporcionarem menorpressão hidráulica, reduzindo a percolação de água através do perfil do solo. Assim, o objetivo do trabalho foi estimar, através de bioensaio, a lixiviação de herbicidas pertencentes ao grupo químico das imidazolinonas frente a diferentes manejos de água de irrigação.

\section{MATERIAL E MÉTODOS}

Foram conduzidos dois experimentos em casa de vegetação na Universidade Federal de Pelotas, Rio Grande do Sul, Brasil. Ambos foram conduzidos em delineamento blocos ao acaso, com quatro repetições e em esquema fatorial. No primeiro experimento, o fator A consistiu de duas misturas formuladas, sendo elas imazethapyr + imazapic e imazapyr + imazapic; o fator B de diferentes manejos de irrigação (contínua, intermitente e capacidade de campo); e o fator $\mathrm{C}$ foi constituído por profundidades de corte da coluna de solo, sendo elas 0-10, 10-20, 20-30 e 30-40 cm). No segundo experimento, o fator A consistiu das mesmas misturas formuladas utilizadas no primeiro experimento mais seus componentes isolados, sendo elesimazethapyr, imazapic e imazapyr; o fator B dos mesmos manejos de irrigação supracitados; e o fator $\mathrm{C}$ de diferentes profundidades de corte da coluna de solo, sendo elas 0-5, 5-10, 10-15, 1520, 20-25, 25-30, 30-35 e 35-40cm).

Para construção das colunas de solo, foram utilizados tubos de PVC de 100x500mm (diâmetro e comprimento, respectivamente) com a base vedada e impermeabilizada com silicone líquido para evitar possíveis perdas de água. Os tubos foram preenchidos com solo, previamente destorroado epeneirado,até a profundidade de $40 \mathrm{~cm}$. O solo foi coletado na área experimental do Centro Agropecuário da Palma/UFPel (31 48'24" S; 52 28'57' O), sendo classificado como PlanossoloHáplicoEutróficoSolódico (unidade de mapeamento Pelotas). As características do solo utilizado 
em ambos os experimentos são: $\mathrm{pH}_{\text {agua }}(1: 1)=5,1$; CTC $\mathrm{pH} 7=5,4 \mathrm{cmol}_{\mathrm{c}} \mathrm{dm}^{-3}$; Matéria Orgânica $=1,2 \%$; argila $=$ $15 \%$; textura $=4 ; \mathrm{Ca}=1,8 \mathrm{cmol} \mathrm{dm}^{-3} ; \mathrm{Mg}=1 \mathrm{cmol} \mathrm{dm}^{-3}$; $\mathrm{Al}$ trocável $=0,2 \mathrm{cmol} \mathrm{dm}^{-3} ; \mathrm{P}$ disponível $=4,3 \mathrm{mg} \mathrm{dm}^{-3}$; $\mathrm{K}$ trocável $=30 \mathrm{mg} \mathrm{dm}^{-3}$.

Os herbicidas foram incubados em 200 gramas de solo e acondicionados na superfície das colunas. As doses utilizadas foram as mesmas recomendadas pela pesquisa, sendo utilizado nos experimentos o equivalente a $1 \mathrm{~L} \mathrm{ha}^{-1}\left(75+25 \mathrm{~g}\right.$ i.a. $\left.\mathrm{L}^{-1}\right)$ para imazethapyr + imazapic; $140 \mathrm{~g} \mathrm{ha}^{-1}(525+175 \mathrm{~g}$ i.a. $\mathrm{L}^{-1}$ ) para imazapyr + imazapic; $75 \mathrm{~g}$ i.a. ha ${ }^{-1}$ para imazethapyr; 73,5g i.a. ha $\mathrm{h}^{-1}$ para imazapyr; e $50 \mathrm{~g}$ i.a. ha $^{-1}$ para imazapic. Após 48 horas de repouso, período necessário para o equilíbrio de sorção herbicida $\mathrm{x}$ solo, iniciaram-se as irrigações. $\mathrm{Na}$ irrigação contínua, foi mantida lâmina de irrigação constante, de aproximadamente cincocentímetros; na irrigação intermitente, permitiu-se que a lâmina de irrigação evaporasse totalmente para promover nova formação de lâmina de água; e solo na capacidade de campo, eram realizadas irrigações semanais. Para atingir a capacidade de campo do solo, as colunas foram pesadas e o volume de água adicionado foi calculado através da diferença entre a coluna de solo no momento da aplicação e na capacidade de campo. Essa etapa do experimento foi conduzida durante um período de 45 e 90 dias para o primeiro e segundo experimentos, respectivamente. Logo após, foi realizado bioensaio para estimar a presença do herbicida nas diferentes profundidades.

Para isso, as colunas de solo foram cortadas longitudinalmente e o solo foi retirado nas diferentes profundidades. Essas amostras de solo foram novamente destorroadas, peneiradas e acondicionadas em vasos plásticos de $700 \mathrm{~mL}$. Foram depositadas cinco sementes por vaso da cultivar de arroz 'IRGA 417', que foi utilizada como planta teste por ser sensível aos herbicidas testados.

As variáveis analisadas foram: avaliação visual da toxicidade dos herbicidas às plantas de arroz aos 14 e 28 DAE (dias após a emergência das plântulas), atribuindo-se valores em percentagem de zero a 100 para ausência de sintomas de fitotoxicidade e morte das plantas, respectivamente; massa da matéria seca (gramas) e estatura da parte aérea (centímetros) das plantas aos $28 \mathrm{DAE}$.

Para análise estatística, as profundidades de corte $(0-10,10-20,20-30,30-40$ e 0-5, 5-10, $10-15,15-20,20-25,25-30,30-35,35-40$, para o primeiro e segundo experimentos, respectivamente) foram consideradas um fator de tratamento, sendo os experimentos analisados como trifatorial. Para ambos os ensaios, os dados foram analisados quanto às pressuposições do modelo matemático (normalidade e homogeneidade das variâncias) e submetidos aos procedimentos de análise da variância (ANOVA $\mathrm{P}<0,05)$. A comparação de médias foirealizadapor intervalo de confiança $(0,95)$ para os manejos de irrigação e profundidade da coluna de solo e pelo teste Tukey $(\mathrm{P}<0,05)$ para os herbicidas testados.

\section{RESULTADOS E DISCUSSÃO}

Todos os dados analisados atenderam as pressuposições do modelo matemático e não foi necessária transformação. Houve interação significativa (ANOVA, Teste $\mathrm{F}, \mathrm{P} \leq 0,05$ ) entre os tipos de irrigação, herbicidas e profundidade de corte das colunas de solo para todas as avaliações realizadas nos dois experimentos. Os resultados obtidos mostram que houve lixiviação das misturas formuladas testadas, sendo os sintomas de toxidez dos herbicidas observados até a profundidade de corte de 30 e $40 \mathrm{~cm}$ para ambas as misturas formuladas (Figuras 1 e 2). A mistura formulada pelos herbicidas imazapyr + imazapic lixiviou mais que imazethapyr + imazapic em ambos os experimentos, principalmente quando submetidas ao manejo de irrigação contínuo, apresentando diferença estatística significativa em quase todas as profundidades de corte testadas. Observa-se que não houve diferença significativa tanto entre as misturas formuladas como entre os manejos de irrigação na camada $0-10 \mathrm{~cm}$, implicando que, mesmo apresentando potencial de lixiviação, tais herbicidas também tendem a concentrar-se mais superficialmente no solo.

Esses resultados corroboram com os encontrados na literatura. Em trabalho realizado por MARTINI et al. (2011), foi constatado, também através de bioensaio, que o herbicida composto pela mistura formulada de imazethapyr e imazapic concentra-se na camada de 5-20cm de profundidade aos 134 dias após a aplicação do produto em solo de cultivo de arroz, indicando ser passível de movimentação ao longo do perfil do solo. Já REFATTI et al. (2012), avaliando a lixiviação das mesmas misturas formuladas através de bioensaio, um ano após a aplicação, verificaram que a lixiviação de imazapyr + imazapic é mais pronunciada do que a de imazethapyr + imazapic, independente das doses aplicadas.

$\mathrm{Na}$ comparação entre os herbicidas isolados, observou-se que o imazapic foi o que mais lixiviou ao longo da coluna de solo, independente do manejo de irrigação utilizado. O imazapyr apresentou menor lixiviação, podendo essa ser observada já 


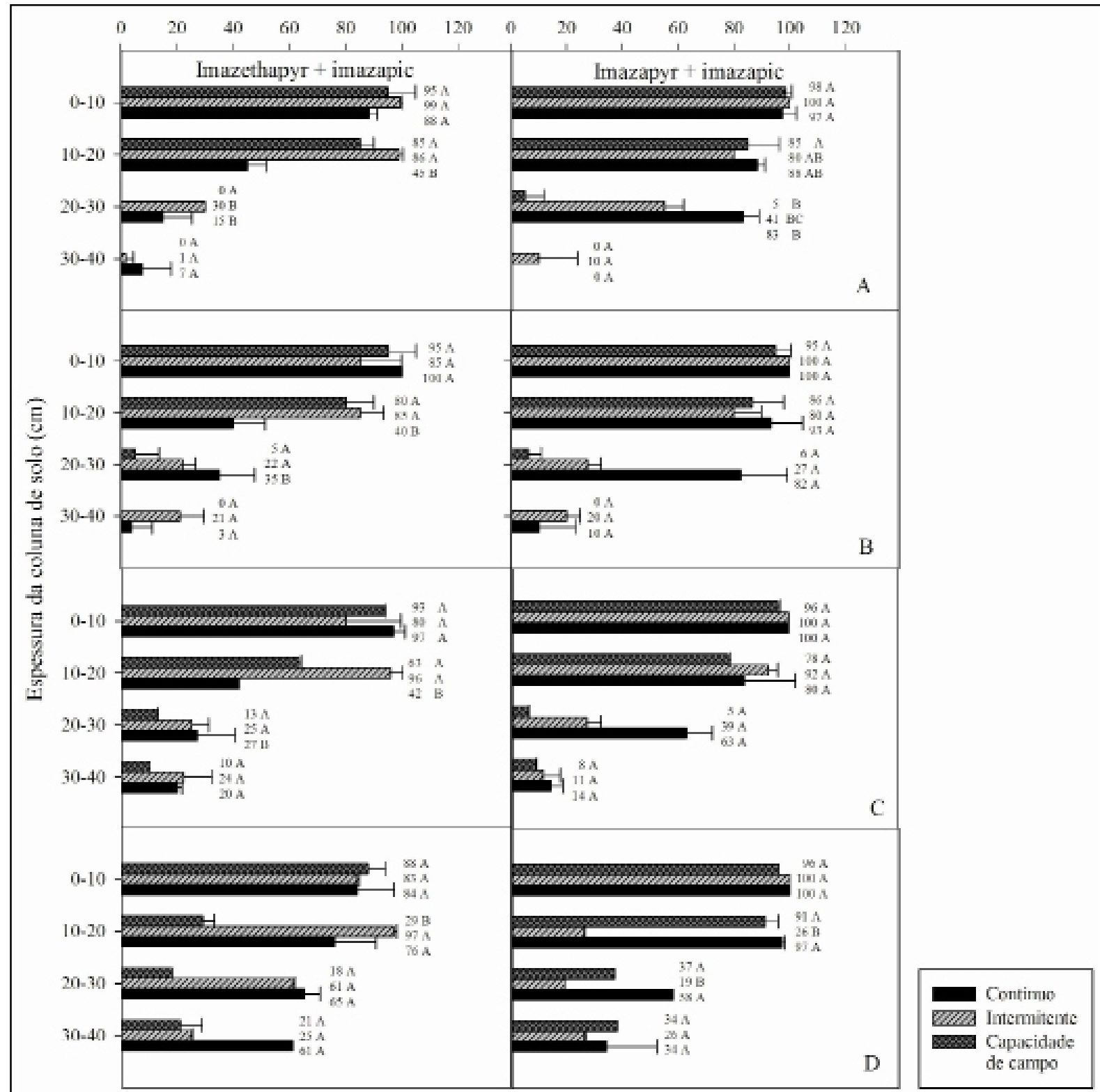

Figura 1 - Estimativa da lixiviação das misturas formuladas imazethapyr + imazapic e imazapyr + imazapic medida através de bioensaio, avaliando a fitotoxicidade aos 14 (A) e 28 (B) dias após a emergência e redução de estatura (C) e massa da matéria seca (D) de plantas de arroz irrigado (IRGA 417), cultivadas em solo proveniente de diferentes camadas das colunas de solo, que permaneceram por 45 dias nos diferentes manejos de irrigação testados. *Médias seguidas pela mesma letra comparam os herbicidas (TukeyP $\leq 0,05$ ); e o intervalo de confiança $(0,95)$ compara os manejos de irrigação.

na profundidade de corte de $0-5 \mathrm{~cm}$. O herbicida imazethapyr apresentou comportamento semelhante ao imazapic nos manejos de irrigação contínua e intermitente até a profundidade de corte de $15-20 \mathrm{~cm}$. Em profundidades superiores, a lixiviação foi menos pronunciada (Figura 2).

A lixiviação dos herbicidas pertencentes ao grupo químico das imidazolinonas é variável, dependendo de uma série de fatores, tanto relacionados ao ambiente em que estão localizados como as próprias características da molécula (SENSEMAN et al., 2007). As principais variáveis relacionadas ao solo são o pH (LOUX \& REESE, 1993), o teor de matéria orgânica (STOUGAARD et al., 1990), a textura (LOUX \& REESE, 1993), o manejo (KRAEMER et al., 2009) e umidade do solo (BAUGHMAN \& SHAW, 1996). Já aquelas relacionadas à molécula são a solubilidade (AVILA 


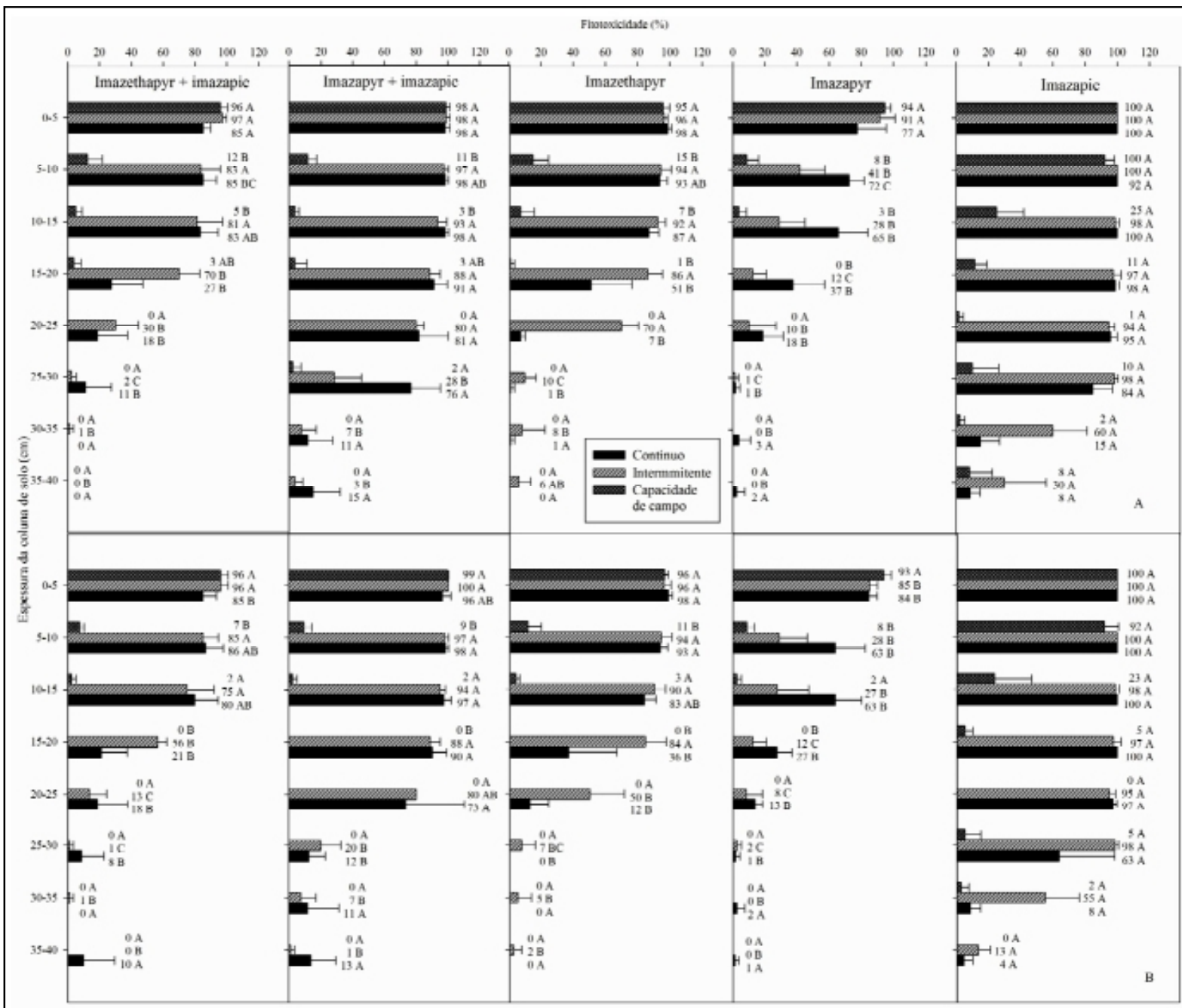

Figura 2 - Estimativa da lixiviação das misturas formuladas imazethapyr + imazapic e imazapyr + imazapic; e dos herbicidas imazethapyr, imazapic e imazapyr medida através de bioensaio, avaliando a fitotoxicidade aos 14 (A) e 28 (B) dias após a emergência de plantas de arroz irrigado (IRGA 417), cultivadas em solo proveniente de diferentes camadas das colunas de solo, que permaneceram por 90 dias nos diferentes manejos de irrigação testados. *Médias seguidas pela mesma letra comparam os herbicidas (TukeyP $\leq 0,05)$; e o intervalo de confiança $(0,95)$ compara os manejos de irrigação.

et al., 2005), capacidade de ionização (INOUE et al., 2007), coeficiente de adsorção ao solo e tipo de degradação. Os aspectos do solo que influem na lixiviação desses herbicidas são já amplamente estudados. JOURDAN et al. (1998) mostraram que imazethapyr movimentou-se ao longo do perfil de um solo arenoso, atingindo $30 \mathrm{~cm}$ de profundidade. KRAEMER et al. (2009) verificaram que o mesmo herbicida lixivia até $20 \mathrm{~cm}$ em solo de cultivo de arroz. O imazapic também apresenta potencial de lixiviação, atingindo até $40 \mathrm{~cm}$ de profundidade em Latossolo de textura média (MONQUERO et al., 2008). Os mesmos autores testaram diferentes valores de $\mathrm{pH}$ $(4,7$ e 6$)$ e verificaram ligeiro aumento da lixiviação na condição de solo mais alcalino. O herbicida imazapyr apresenta resultados contraditórios quanto à lixiviação. FIRMINO et al. (2008), estudando a lixiviação desse herbicida em solos com diferentes texturas, verificaram maior lixiviação, em ordem decrescente, nos solos com textura francoarenoso > franco-argilo-arenoso > muito argiloso, e que a movimentação foi tanto descendente como ascendente. Em contrapartida, resultados observados por WEHTJE et al. (1987) mostram maior mobilidade do imazapyr em solos argilosos e também que essa mobilidade diminuiu com a redução da umidade e do pH do solo. A divergência entre os resultados de lixiviação pode estar relacionada com fatores diretamente relacionados com sítios de adsorção do solo, tais como teor de matéria orgânica 
e características mineralógicas e/ou com a própria degradação do herbicida no solo.

Os dados de redução de massa da matéria seca e estatura das plantas bioindicadoras mostraramse semelhantes aos de fitotoxicidade, evidenciando que houve lixiviação do herbicida ao longo das colunas de solo e que os manejos de irrigação contínuo e intermitente foram os que promoveram maior movimento dos herbicidas (Figura 1).

$\mathrm{Na}$ comparação entre os manejos de irrigação, não foi obervada diferença significativa entre o contínuo e o intermitente para a maioria das profundidades de corte da coluna para o segundo experimento (Figura 2). Tal comportamento difere dos resultados obtidos no primeiro experimento, que mostrou maior lixiviação de imazapyr + imazapic em manejo de irrigação contínuo. Isso pode ser consequência do tempo de incubação dos herbicidas nas colunas de solo, sendo de 45 e 90 dias para o primeiro e segundo experimentos, respectivamente. A lixiviação dos herbicidas no manejo de irrigação contínuo provavelmente ocorreu mais rapidamente que no manejo intermitente; diferença essa que não foi observada no segundo experimento, em que o maior tempo de incubação provavelmente proporcionou que o manejo intermitente expressasse toda sua influência na lixiviação dos herbicidas. Convém ressaltar que esse tempo de incubação não foi testado no trabalho, sendo necessário mais estudos para confirmar tal suposição.

O aumento na lixiviação dos herbicidas no manejo de irrigação contínuo, ou seja, que promove a formação de lâmina de irrigação durante praticamente todo o ciclo da cultura, já era esperado, visto que o fluxo da água no solo, juntamente com o herbicida, é descendente, devido à pressão hidráulica causada pela inundação. Geralmente, em condição de lavoura de arroz irrigado, o solo permanece com lâmina de água por até 100 dias, o que faz com que os herbicidas se concentrem em profundidades a partir dos 10 até os $20 \mathrm{~cm}$ do perfil do solo (KRAEMER et al., 2009; MARTINI et al., 2011). Estando nessas profundidades, os herbicidas são degradados em menor proporção, devido à menor atividade microbiana, o que pode aumentar a sua persistência no ambiente.

A elevada lixiviação nos manejos de irrigação que promoveram o encharcamento do solo também é explicada pelo comportamento desses herbicidas em condições de excesso hídrico. O aumento da umidade do solo interfere diretamente na disponibilidade de um herbicida, ou seja, na concentração presente na solução do solo. Por exemplo, a disponibilidade de imazethapyr ocorre rapidamente após o alagamento, visto que o teor de água aumenta a solubilidade destes herbicidas (AVILA et al., 2005).

Todos os herbicidas apresentaram menor lixiviação quando o solo foi mantido na capacidade de campo. Isso ocorreu em virtude da menor percolação de água pelo perfil do solo, assim como pela sua maior aeração que, possivelmente, devido à atividade microbiana, pode ter proporcionado maior degradação dos herbicidas (LOUX et al., 1989). Segundo MARTINI et al. (2011), a irrigação, independentemente do seu manejo, promove movimento vertical do herbicida, sendo menos intensificado na irrigação por banhos. Tal irrigação consiste na utilização de $30 \mathrm{~mm}$ de volume de água em intervalos variáveis, dependendo da evapotranspiração e de aspectos climáticos, e mostrase semelhante ao manejo de irrigação adotado no presente experimento, que foi denominado solo na capacidade de campo.

Em suma, os resultados obtidos no presente artigo podem auxiliar no entendimento do comportamento das imidazolinonas em condição de cultivo com arroz irrigado. Todas as questões referentes à dinâmica de herbicidas no ambiente devem ser analisadas em conjunto, principalmente para herbicidas com elevada mobilidade e degradação limitada no solo. É importante ressaltar que muitas vezes as práticas de manejo adotadas pelos produtores interferem diretamente na dinâmica das moléculas e que esses dificilmente deixarão de utilizá-las enquanto forem de alto retorno econômico. Por exemplo, o manejo de água adotado pela maioria dos orizicultores é o de irrigação com entrada contínua de água, devido ao menor risco de déficit hídrico e auxílio no controle de plantas daninhas. A partir daí, mesmo sendo potencial causador de contaminação ambiental, tal manejo não deixará de ser utilizado. Cabe aos pesquisadores buscar alternativas que minimizem o problema de contaminação sem causar redução de produtividade e rentabilidade.

\section{CONCLUSÃO}

Os manejos de irrigação contínuo e intermitente intensificam a lixiviação de imidazolinonas. A mistura formulada por imazapyr + imazapicapresentamaior lixiviação ao longo do perfil do solo. Para os herbicidas testados isoladamente, o imazapic apresenta maior livixiação, seguido do imazethapyr e imazapyr. 


\section{REFERÊNCIAS}

AGROFIT, 2014 - Desenvolvido pelo Ministério da Agricultura, Pecuária e Abastecimento. 2001. Disponível em: <http://www. agricultura.gov.br/agrofit.> Acesso em: 15 jan. 2014.

AVILA, L.A. et al. Efeito da umidade do solo na sorção e disponibilidade de imazethapyr em três solos. In: CBAI, 4.; REUNIÃO DA CULTURA DO ARROZ IRRIGADO, 26.; 2005 , Santa Maria, RS. Anais... Santa Maria: UFSM, 2005. p.190-193.

BAUGHMAN, T.A.; SHAW, D.R. Effect of wetting/drying cycles on dissipation patterns of bioavailable imazaquin. Weed Science, v.44, n.2, p.380-382, 1996. Disponível em: <http://europepmc. org/abstract/AGR/IND21984334/reload=0; jse ssionid=uBmY BeYDzQR05XoG6UAL.34.> Acesso em: 08 fev. 2013. doi: AGR:IND21984334.

BELDER, P. et al. Effect of water-saving irrigation on rice yield and water use in typical lowland conditions in Asia Agricultural Water Management, v.65, n.3, p.193-210, 2004. Disponível em: <http://www.sciencedirect.com/science/article/pii/ S0378377403002440.>. Acesso em: 13 fev. 2013.doi: 10.1016/j. agwat.2003.09.002.

BUNDT, A.D.C. et al. Transporte ascendente da mistura formulada de imazethapyr e imazapic em resposta à profundidade do lençol freático. Ciência Rural, v.43, n.9, p.1597-1604, 2013. Disponível em: <http://www.scielo.br/scielo.php?script=sci_arttext\&pid=S01 0384782013000900010\&lng=pt\&nrm=iso\&tlng=pt..> Acesso em: 25 ago. 2013. doi: 10.1590/S0103-84782013005000111.

FIRMINO, L.E. et al. Movimento do herbicida imazapyr no perfil de solos tropicais. Planta Daninha, v.26, n.1, p.223-230, 2008. Disponível em: <http://www.scielo.br/scielo.php?pid=S0100$83582008000100023 \&$ script $=$ sci_arttext. $>$. Acesso em: 21 nov. 2009. doi:10.1590/S0100-83582008000100023.

FLINT, J.L.; WITT, W.W. Microbial degradation of imazaquim and imazethapyr. Weed Science, v.45, n.4, p.586-591, 1997. Disponível em: <http://www.jstor.org/discover/10.2307/4045996?uid=3737664 \&uid=2\&uid=4\&sid=21102592092487 > . Acesso em: 23 abr. 2012.

INOUE, N.H. et al. Potencial de lixiviação de imazapic e isoxaflutole em colunas de solo. Planta Daninha, v. 25, n.3, p.547555, 2007. Disponível em: <http://www.scielo.br/pdf/pd/v25n3/14 pdf>. Acesso em: 22 dez. 2013.doi: S0100-83582007000300014.

JOURDAN, S.W. et al. Imazethapyr bioactivity and movement in soil. Weed Science, v.46, n.5, p.608-613, 1998. Disponível em: <http://www.jstor.org/discover/10.2307/4045969?uid=3737664\& uid $=2 \&$ uid $=4 \& \operatorname{sid}=21102592092487>$. Acesso em: 27 nov. 2012 .

KRAEMER, A.F. et al. Lixiviação do imazethapyr em solo de várzea sob dois sistemas de manejo. Ciência Rural, v.39, n.6, p.1660-1666, 2009. Disponível em: <http://www.scielo.br/scielo. php?script=sci_pdf\&pid=S010083582009000300020\&lng $=$ en $\& n r$ $\mathrm{m}=\mathrm{iso} \& \operatorname{lng}=\mathrm{pt}>$. Acesso em: 14 mar. 2010. doi:10.1590/S010083582009000300020

LOUX, M.M. et al. Adsorption of imazaquim and imazethapyr on soils, sediments and selected adsorbants. Weed Science, v.37, n.5, p.712-718, 1989. Disponível em: <http://europepmc.org/abstract/ AGR/IND90003909>. Acesso em: 06 fev. 2013. doi: AGR/ IND90003909.

LOUX, M.M.; REESE, K. Effect of soil type and $\mathrm{pH}$ on persistence and carryover of imidazolinones herbicides. Weed Technology, v.7, n.2, p.452-458, 1993. Disponível em: <http://www.jstor. org/stable/4045295>. Acesso em: 12 out. 2008. doi:10.2134/ jeq2002.6130.

MARTINI, L.F.D. et al. Lixiviação de imazethapyr + imazapic em função do manejo de irrigação do arroz. Planta daninha, v.29, n.1, p.185-193, 2011. Disponível em: <http://www.scielo.br/scielo. php?pid=S0100-83582011000100021\&script=sci_arttext. Acesso em: 7 mar. 2013>. doi: 10.1590/S0100-83582011000100021.

MONQUERO, P.A. et al. Potencial de lixiviação de herbicidas no solo submetidos adiferentes simulações de precipitação. Planta Daninha, v.26, n.2, p.403-409, 2008. Disponível em: <http://www.scielo.br/scielo.php?pid=S0100$83582008000200017 \&$ script=sci_arttext. Acesso em: 11 out. 2012. doi: 10.1590/S0100-83582008000200017>.

REFATTI, J.P. et al. Potencial de lixiviação de herbicidas do Sistema Clearfield $^{\circledR}$ em solo de várzea. In: CONGRESSO BRASILEIRO DA CIÊNCIA DAS PLANTAS DANINHAS, 2012, Campo Grande, MS. Anais... Campo Grande: SOSBAI, 2012. p.287-292.

SENSEMAN, S.A. et al. Herbicide handbook. Lawrence: Weed Science Society of America, 2007. 458p.

STOUGAARD, R.N. et al. Effect of soil type and $\mathrm{pH}$ on adsorption, mobility and efficacy of imazaquim and imazethapyr. Weed Science, v.36, n.1, p.67-73, 1990. Disponível em: <http:// europepmc.org/abstract/AGR/IND90038427>. Acesso em: 05 fev. 0213. doi: AGR:IND90038427.

TU et al. Imazapic. In: Weed control methods handbook. Weed control methods handbook. London: Academic, 2004. Cap.7, p.1-7.

WEHTJE, G. et al. Sorption and mobility of sulfometuron and imazapyr in five Alabama soils. Weed Science, v.35, n.6, p.858864, 1987. Disponível em: <http://www.jstor.org/discover/10.2307 /4044584 ?uid $=3737664 \&$ uid $=2 \& u i d=4 \&$ sid $=21102592092487>$. Acesso em: 9 set. 2012. 